\title{
Radiochemical Detection for Packed Capillary Liquid Chromatography-Mass Spectrometry
}

\author{
Bruce Charles Onisko \\ Jealotts Hill Research Center, Syngenta, Bracknell, Berkshire, United Kingdom
}

For the identification of trace level organic molecules, such as drug or pesticide metabolites, there is need of a practical method to do packed capillary liquid chromatography-mass spectrometry (LC-MS) with radiochemical detection. This problem has been successfully solved by use of a post column flow-splitter, with coaxially transported makeup flow that increases the split flow rate to a flow compatible with commercially available radiochemical flow cells. To test the device, ${ }^{14} \mathrm{C}$-labeled azoxystrobin, a commercial fungicide, was analyzed by liquid chromatography-radiochemical activity monitor-mass spectrometry (LC-RAM-MS) using a $0.32 \mathrm{~mm}$ i.d. packed capillary column. Azoxystrobin could be detected at $500 \mathrm{pCi}$ with good signal/noise. The method is general and can be used with capillary LC columns of smaller diameters. Column efficiency of about 20,000 theoretical plates/m was achieved using either radiochemical or mass spectrometric data, thus demonstrating the lack of band broadening using the described method for radiochemical detection. The simple hardware described allows the routine use of packed capillary LC with radiochemical detection. (J Am Soc Mass Spectrom 2002, 13, 82-84) (C) 2002 American Society for Mass Spectrometry

$\mathrm{F}$ or concentration-dependent detectors such as electrospray ionization or ultraviolet absorption, chromatographic miniaturization gives chromatographic peaks of greater concentration and thus of significantly larger signal to noise ratio. For example, injection of the same amount of analyte on chromatographic columns of either $4.6 \mathrm{~mm}$ i.d. or $0.32 \mathrm{~mm}$ i.d., but with the same lengths and linear flow rates, the analyte concentration should be about 200-fold greater from the packed capillary column $\left[(4.6 / 0.32)^{2}\right]$. The practical result is that much less material is needed for the analyses using smaller diameter columns.

Historically, packed capillary liquid chromatography was routinely used for unknown identification using flow FAB (fast atom bombardment) interfaces [1, 2]. The commercial FAB sources were ideally suited for use with packed capillary chromatographic columns since the flow rate requirements of the column and source were compatible. Application of the solvent focusing effect enabled packed capillary chromatographic columns to be used when only small amounts of sample were available, since the entire sample could be injected onto the column [3].

The flow FAB interface, however, suffered from several drawbacks, chief among them being the complexity of operation and the high instrumental background caused by the FAB matrix (e.g., glycerol). Both

Published online November 27, 2001

Address reprint requests to Dr. B. C. Onisko, Jealotts Hill Research Center, Syngenta, Bracknell, Berkshire RG42 6EY, United Kingdom. E-mail: OniBid@cs.com of these problems were solved by development of the electrospray ionization (ESI) source, which has been used extensively for unknown identification since 1989 [4]. In addition, the ESI source could be used with the flow rates of conventional chromatographic columns (2-4.6 mm i.d.), and commercial technology could be used for radiochemical detection. On-line radiochemical detection greatly simplifies identification of radiolabeled unknowns by LC-MS since the selectivity of the radiochemical signal reveals where the unknown of interest eluted, if the chromatography was working properly, how much unknown was actually injected, and if the sample had decomposed before analysis.

On-line radiochemical detection is routinely used with LC when column diameters are greater than $2 \mathrm{~mm}$ using radiochemical cells with either solid scintillant particles or liquid scintillant cocktail [8]. Commercial cells using solid scintillant particles are available with only 5 microL cell volume and can be used with LC columns of $0.8 \mathrm{~mm}$ i.d. or larger [Personal communication, John E. Hnizdil of IN-US, January 12th, 2001]. However, the unavailability of smaller volume radiochemical detector cells prevents the use of packed capillary chromatographic columns of smaller diameter with radiochemical detection.

Considerable work has been done to develop methods for on-column radioisotope detection for capillary zone electrophoresis (CZE) [5, 6]. The CZE methods detect beta particles that have sufficient energy to escape through the fused silica capillary and interact with a solid scintillant to emit photons. In principle, this method could be used for packed capillary LC as well 
as for capillary electrophoresis, however their use with packed capillary LC has not been reported. This is most likely because the most useful isotopes for metabolite identification, ${ }^{3} \mathrm{H}(19 \mathrm{keV})$ and ${ }^{14} \mathrm{C}(156 \mathrm{keV})$, are not sufficiently energetic for sensitive through-column detection. (The minimum detectable energy has been calculated to be about $150 \mathrm{keV}$ for a 100 microm i.d. column with 125 microm fused silica walls [7]).

One solution to enable LC-RAM-MS analysis using packed capillary LC columns has been reported. The method requires fabrication of a packed capillary column with incorporation of the radiochemical cell within the custom-made column [9]. We herein report a much more simple solution to this analytical problem which requires no custom-made hardware.

\section{Experimental}

\section{Chemicals}

Azoxystrobin (15 Ci/mole-U-C14) was prepared for use in metabolism studies at the Western Research Center of Syngenta (Richmond, CA). LC grade acetonitrile and water were from Fisher Scientific (Pittsburg, PA).

\section{Instrumentation}

LC-MS was performed on a Finnigan-MAT (San Jose, CA) Model TSQ700 triple quadrupole mass spectrometer equipped with an electrospray ionization source. The ESI source was operated at $3.5 \mathrm{kV}$ potential and with a heated capillary temperature of $200{ }^{\circ} \mathrm{C}$. Nitrogen gas was used at a sheath gas pressure of 50 psi. Auxiliary gas flow was adjusted to achieve a total flow of $0.5 \mathrm{~L} / \mathrm{min}$ of nitrogen.

Mobile phase was prepared which contained 50/50 (vol/vol) acetonitrile/aqueous $0.1 \%$ acetic acid and was pumped at $200 \mathrm{microL} / \mathrm{min}$ and 3,200 psi with a Perkin-Elmer Model 250 LC (Norwalk, CT) to a splitter connected to (1) an LC column used as a flow resistor (1 $\mathrm{mm}$ i.d. by $100 \mathrm{~mm}$ long ABI Spheri-5 RP-18, 5 microm) and (2) a Rheodyne Model 8125 injector (Cotati, CA) with a 10 microL sample loop. A $0.322 \mathrm{~mm}$ i.d. by 150 mm long capillary LC column packed with Spherisorb ODS-2 (3 microm) from LC Packings (San Francisco, CA) was connected to the outlet of the Rheodyne injector. A flow rate of $7 \mathrm{microL} / \mathrm{min}$ through the microbore LC column was achieved empirically by adjusting the total flow from the Perkin-Elmer pump to $0.2 \mathrm{~mL} / \mathrm{min}$.

The flow from the analytical LC column was split such that $3.5 \mathrm{microL} / \mathrm{min}$ flowed to the ESI source using $10 \mathrm{~cm}$ of 50 microm i.d. fused silica capillary tubing (FSC, Polymicro Technologies, Phoenix, Arizona). The remaining flow from the splitter was diverted via $1 \mathrm{~m}$ of 70 microm i.d. FSC tubing (Polymicro Technologies) to a Ramona Model 5-LS radiochemical detector equipped with a radiochemical liquid cell (1.2 $\mathrm{mL}$ cell volume) using scintillant (Scintisafe Econo 2

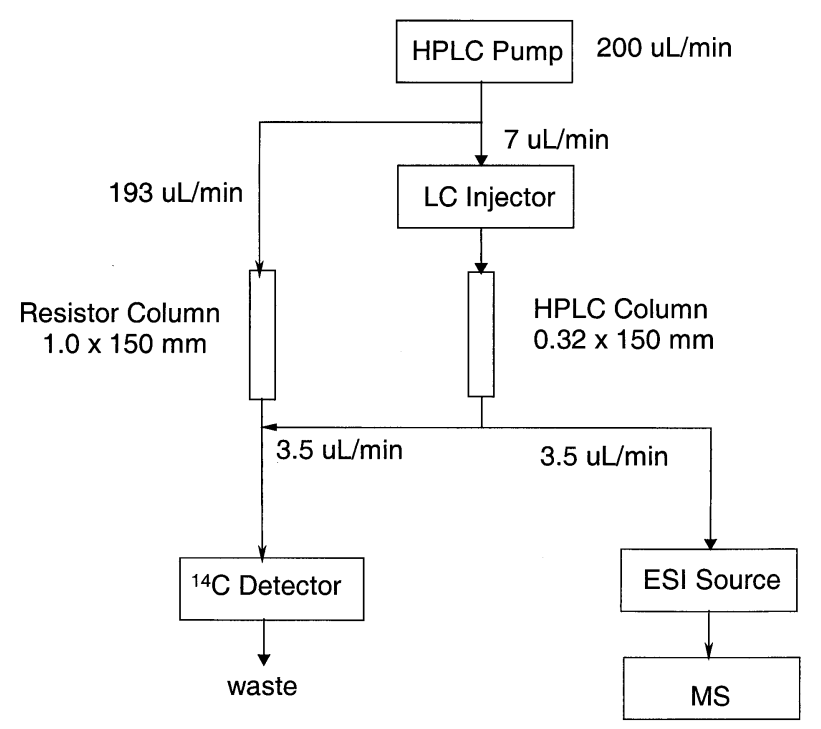

Figure 1. Hardware schematic using a post column low dead volume flow-splitter with makeup flow to match the column flow rate to the cell volume of a commercially available radiochemical flow cell.

from Fisher Scientific) at a flow of $5 \mathrm{~mL} / \mathrm{min}$. The flow from the $1 \mathrm{~mm}$ i.d. resistor column was used as makeup flow to give a total flow of about $0.2 \mathrm{~mL} / \mathrm{min}$ compatible with the radiochemical liquid cell. The connection of the flows from the analytical column and the resistor column follows the design of the CZE-MS sheath flow interface [10]. The $1 \mathrm{~m}$ of 70 microm i.d. FSC tubing was run coaxially within a length of $1 / 16$ th o.d. PEEK tubing such that the flows described did not actually mix until they entered the radiochemical detection cell.

\section{Results and Discussion}

The experimental method described in this paper uses a post column low dead volume flow-splitter, with makeup flow to increase the total flow to a value compatible with commercially available radiochemical flow cells. The hardware schematic is shown in Figure 1. The connection of the flows from the analytical column and the resistor column was designed to maintain laminar flow, and thereby minimize band broadening. The fused silica tubing exiting the post column low dead volume flow-splitter was run coaxially within $1 / 16$ th o.d. PEEK tubing such that the column flow did not actually mix with the makeup flow until both entered the radiochemical detection cell. Furthermore, the stainless steel T-piece used to connect the flows from the analytical and resistor columns was electrically grounded to decrease noise in the radiochemical detector.

The radiochemical cell volume and scintillant flow rate were chosen to have a residence time of about 0.2 min (1.2 mL cell volume $/ 5.2 \mathrm{~mL} / \mathrm{min}$ flow rate) which is less than the width at half height of the chromatographic peaks (about $0.3 \mathrm{~min}$ ) to minimize peak broad- 


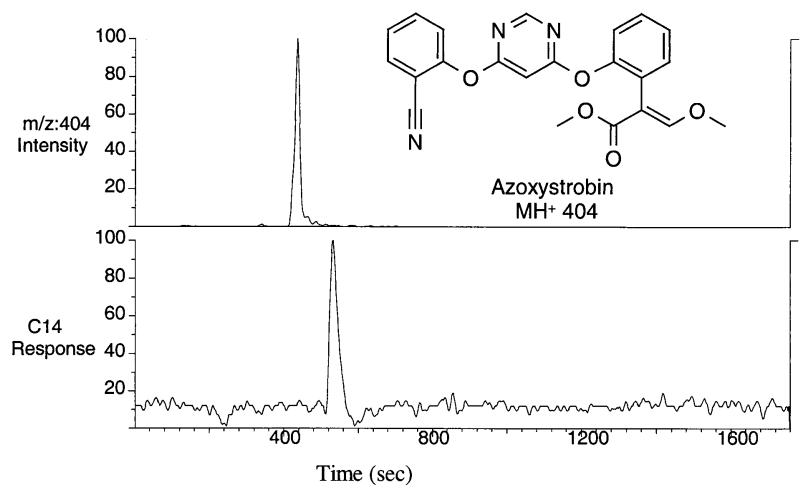

Figure 2. Mass chromatogram (top) and radiochromatogram (bottom) obtained from injection of $930 \mathrm{pCi}(25 \mathrm{ng}$ ) of azoxystrobin (15 Ci/mole-U-C14) on the packed capillary column shown in Figure 1. The y-axis for both traces is shown as a $\%$ of maximum response obtained. The radiochemical output is delayed by about $1 \mathrm{~min}$ because of the longer tubing required to connect this detector.

ening, but large enough to obtain sufficient time for observing radioactive disintegrations to optimize radioactive detection. Proportionally smaller radiochemical cells and scintillant flow rates can be used, and if the residence time remains the same, the detector performance should remain unchanged. Furthermore, radiochemical cells packed with solid scintillant particles cannot be used for the application described because of the high back pressures of such cells and the subsequent difficulty in obtaining the desired split ratio.

To test the apparatus, azoxystrobin $(930 \mathrm{pCi}, 15$ $\mathrm{Ci} /$ mole-U-C14, $25 \mathrm{ng}$ ), a commercial fungicide, the metabolism of which is under investigation in our laboratory, was injected on a packed capillary column in $5 \mathrm{uL}$ of water to effect solvent focusing. The resulting radiochromatogram is shown in Figure 2. The top trace is the intensity of the protonated molecule observed at $\mathrm{m} / \mathrm{z}$ 404. The bottom trace is the output of the radiochemical detector. Due to the 50/50 split to the two detectors, only $460 \mathrm{pCi}(1000 \mathrm{dpm})$ of ${ }^{14} \mathrm{C}$ entered the radiochemical cell. A signal/noise of about $20 / 1$ was achieved which is similar to detection of ${ }^{14} \mathrm{C}$ seen with conventional LC-RAM. For example, $4.6 \mathrm{~mm}$ i.d. LC columns are often run at $1 \mathrm{~mL} / \mathrm{min}$ with $1 \mathrm{~mL}$ flow cells and $4 \mathrm{~mL} / \mathrm{min}$ scintillant. A peak containing $1000 \mathrm{dpm}$ at $65 \%$ counting efficiency will generate only 130 counts (1000 dpm* $0.65 \mathrm{cpm} / \mathrm{dpm}^{*} 1.0 \mathrm{~mL} / 5.0 \mathrm{~mL} / \mathrm{min}$ ) in the 0.2 min residence time. At a background level of 15 cpm, 3 counts of background will be observed in the same time period $\left(15 \mathrm{cpm}^{*} 1.0 \mathrm{~mL} / 5.0 \mathrm{~mL} / \mathrm{min}\right)$ to give an overall $\mathrm{S} / \mathrm{N}$ of about $40 / 1$.

Triplicate injections of azoxystrobin resulted in a calculated column efficiency of $21,400+/-5,400$ theoretical plates/m (mean $+/$ - standard deviation for three observations) using radiochemical data and 19,500 $+/-5,500$ theoretical plates/m (mean +/ - standard deviation for three observations) using mass spectrometric data. This demonstrates the lack of band broadening using the described hardware for radiochemical detection.

\section{Acknowledgments}

The author wishes to acknowledge Paul Cooper for his contribution in discussions that led to the design described.

\section{References}

1. Caprioli, R. M.; DaGue, B.; Fan, T.; Moore, W. T. Biochem. Biophys. Res. Commun. 1987, 146, 291-299.

2. Caprioli, R. M.; Fan, T.; Cottrell, J. S. Anal. Chem. 1986, 58, 2949-2954.

3. Onisko, B. C. Eighth International Congress of Pesticide Chemistry Options 2000. American Chemical Society: Washington, DC, 1995; pp 269-277.

4. Fenn, J. B.; Mann, M.; Meng, C. K.; Wong, S. F.; Whitehouse, C. M. Science 1989, 246, 64-71.

5. Pentoney, S. L.; Zare, R. N. Anal. Chem. 1989, 61, 1642-1647.

6. Klunder, G. L.; Andrews, J. E.; Grant, P. M.; Andresen, B. D. Anal. Chem. 1997, 69, 2988-2993.

7. Knoll, G. Radiation Detection and Measurement, 2nd edition. J. Wiley \& Sons: New York, 1989; pp 45-47.

8. Kessler, M. J. Analytical and Chromatographic Techniques in Radiopharmaceutical Chemistry. Springer-Verlag: New York, 1987 Chap V-VII.

9. Schultz, G. A.; Alexander, J. N. J. Microcol. Sep. 1998, 10, 431-437.

10. Smith, R. D.; Barinaga, C. J.; Udseth, H. R. Anal. Chem. 1988, 60, 1948-1952. 